\title{
Stray dog meat consumption and rebies
}

\author{
Viroj Wiwanitkit \\ Visiting professor, Hainan Medical Univesity, China
}

Sir, the recent report on "stray dog trade, dog meat consumption and rabies" is very interesting [1]. Ekanem et al. noted that ": stray dog trade, fuelled by eating of dog meat, is a risk factor for human and animal rabies in Calabar, southern Nigeria [1]." In fact, eating of dog meat is not a usual way that rabies can be transmitted but getting dog bite during the process of stray dog collection and transportation is more possible. However, it should not be forgotten that the contamination of rabies virus in brain and nervous tissue of rabid dog is possible and this can also be the source of infective pathogen to ones who directly contact it [2]. Of interest, according to a recent report by Odeh et al., $3.9 \%$ of studied brains samples from sold dogs could be identified for rabies antigen [2]. Hence, the specific method for controlling of rabies among the dog meat trade is needed. One who involves in this trade should get the pre exposure rabies vaccination. Also, consumer who loves to eat dog meat should also be vaccinated. Finally, in additional to rabies, other diseases directly relating to ingestion of dog meat such as helminthic infestations should not be overlooked. The good example is the trichinellosis which can be a result from intake of contaminated dog meat.

DOI: http://dx.doi.org/10.4314/ahs.v14i3.41

\section{Corresponding author:}

Professor Viroj Wiwanitkit

Wiwanitkit House, Bangkhae, Bangkok

Thailand 10160

Email:wviroj@yahoo.com

\section{References:}

1. Ekanem E, Eyong K, Philip-Ephraim E, Eyong M, Adams E, Asindi A. Stray dog trade fuelled by dog meat consumption as a risk factor for rabies infection in Calabar, southern Nigeria. Afr Health Sci. 2013 Dec;13(4):1170-3.

2. Odeh LE, Umoh JU, Dzikwi AA. Assessment of risk of possible exposure to rabies among processors and consumers of dog meat in Zaria and Kafanchan, Kaduna state, Nigeria. Glob J HealthSci. 2013 Nov 3;6(1):14253. 